\title{
ARTICLES
}

\section{Bilirubin Induces Apoptosis and Necrosis in Human NT2-N Neurons}

\author{
ERIK HANKØ, THOR WILLY RUUD HANSEN, RUNAR ALMAAS, JULIE LINDSTAD, AND \\ TERJE ROOTWELT \\ Department of Pediatric Research [E.H., R.A., J.L., T.R.], Department of Pediatrics [T.W.R.H., T.R.], \\ Rikshospitalet, 0027 Oslo, Norway, Department of Pediatrics [R.A.], Sykehuset Østfold, 1607 Fredrikstad, \\ Norway
}

\begin{abstract}
Studies on primary cultures of newborn rodent neurons have suggested that neuronal death induced by unconjugated bilirubin (UCB) is mainly apoptotic in nature. We exposed a human teratocarcinoma-derived cell line, NT2-N neurons, to different concentrations of UCB and albumin at a 1.5 molar ratio and used multiple, independent measures of cell damage to evaluate neuronal injury after 6,24 , and $48 \mathrm{~h}$. Low doses of $\operatorname{UCB}(0.66,2$, and $5 \mu \mathrm{M}$ ) induced a moderate loss of 3-4[4,5-dimethylthiazol2-yl]-2,5-diphenyltetrazoliumbromide (MTT) cleavage accompanied by delayed morphologic changes consistent with apoptosis $(2$ and $5 \mu \mathrm{M})$. Moderate concentrations of UCB (10 and 25 $\mu \mathrm{M})$ resulted in early $(6 \mathrm{~h})$ necrosis in a subset of neurons, while remaining neurons underwent progressive impairment of MTT cleavage and increasing lactate dehydrogenase (LDH) release accompanied by predominantly delayed apoptosis. High concentrations of UCB $(100 \mu \mathrm{M})$ induced severe impairment of MTT cleavage, extensive LDH release, and morphologic changes consistent with necrosis within $6 \mathrm{~h}$. Used as a positive control for apoptosis, $2 \mu \mathrm{M}$ STS induced progressive impairment of MTT cleavage and morphologic changes consistent with apoptosis
\end{abstract}

\section{ABSTRACT}

over the entire observation period. DNA electrophoresis at $48 \mathrm{~h}$ was compatible with apoptosis both after treatment with STS and UCB concentrations $\leq 25$, but not at $100 \mu \mathrm{M}$. Cleavage of poly (ADP-ribose) polymerase (PARP) was only seen in neurons treated with low UCB concentrations and STS. We conclude that UCB induces early necrosis at high and moderate concentrations and predominantly delayed apoptosis at low and moderate concentrations in cultured human NT2-N neurons. (Pediatr Res 57: 179-184, 2005)

\[ \text { Abbreviations } \]
BSA, bovine serum albumin
EH, ethidium homodimer
HSA, human serum albumin
LDH, lactate dehydrogenase
MR, molar ratio
MTT, 3-4[4,5-dimethylthiazol-2-yl]-2,5-
diphenyltetrazoliumbromide
UCB, unconjugated bilirubin

Bilirubin-induced encephalopathy in the newborn has been described for over a century. The term is mainly used to describe a picture of reversible lethargy and alterations in cerebral evoked potentials thought to be benign (1). The term kernicterus has been used to describe more severe clinical manifestations like seizures, opisthotonos, and hyperthermia in the acutely ill newborn, followed by neurologic sequelae in

Received January 7, 2004; accepted August 18, 2004.

Corresponsdence: Erik Hank $\varnothing$, M.D., Rikshospitalet, Department of Pediatric Research, N-0027 Oslo, Norway; e-mail: erikh@klinmed.uio.no

This study was supported by the University of Oslo, Norwegian Research Council, Anders Jahres Foundation, the Blix Family Foundation, the Laerdal Foundation for Acute Medicine, and the Odd Fellow Foundation.

DOI: 10.1203/01.PDR.0000148711.11519.A5 survivors or death (1). The question of whether these manifestation share a common graded mechanism or reflect different entities is not settled (2).

Previously, neuronal death has been thought of as the result of either necrosis or apoptosis (3). However, it now seems that apoptosis and necrosis represent extreme ends of a spectrum of possible biochemical and morphologic deaths, so that a more dynamic boundary between apoptosis and necrosis has been suggested (3). Several studies have shown that it is often the magnitude of the initial insult, rather than the specific type of the stimulus, that determines whether the cell undergoes either type of cell death $(3,4)$. Recently, several studies have reported that UCB primarily induces apoptosis both in primary cultures of fetal cortical and cerebellar rodent neurons $(5,6)$, in cultures 
of fetal rodent astrocytes $(7,8)$, and in murine hepatoma cells (9). Despite these studies, it remains unclear 1) whether the cells die by apoptosis, necrosis, or both; 2) whether the UCB concentration is decisive for the relative proportion of apoptosis and necrosis; and 3) how neuronal death evolves with time. Furthermore, all studies addressing the issue of UCB-induced cell death mechanisms so far have been undertaken in neuronal cultures from rodents or on non-neuronal cells. We have used a human teratocarcinoma-derived cell line, NT2-N cells, to study UCB-induced cell death. After treatment with retinoic acid and mitotic inhibitors, these cells develop into polarized, postmitotic, neuron-like cells that share many characteristics with CNS neurons (10). They express functional non-NMDA as well as NMDA-receptors (11), different types of calcium channels (12), and elaborate classical synaptic contacts (13). In this descriptive study, we determined the modes of cell death in NT2-N neurons and its temporal evolution after exposure to various concentrations of bilirubin. We demonstrate that bilirubin induces early necrosis-like cell death and delayed apoptosis-like cell death in a concentration-dependent manner in this cell line.

\section{MATERIALS AND METHODS}

Materials. Dulbecco's medium modified by Eagle (DMEM), fetal bovine serum (FBS), and PBS were purchased from Invitrogen (Carlsbad, CA). Penicillin and streptomycin were also purchased from Invitrogen, while polylysine and Matrigel were purchased from BD Biosciences (San Jose, CA). Bilirubin, BSA, MTT, retinoic acid, uridine, 5-fluoro-2'-deoxyuridine, and cytarabine were from Sigma Chemical Co. (St. Louis, MO). BSA was dissolved in deionized water. MTT was dissolved in PBS with glucose. The fluorescent dyes Hoechst 33342 and EH (both from Molecular Probes, Eugene, OR) were diluted in DMSO to $5 \mathrm{mg} / \mathrm{mL}$ and $2 \mathrm{mM}$ stocks, respectively.

NTera2/c1.D1 (NT2) cells were cultured as previously described (14). In short, cells were plated at a density of $2.3 \times 10^{6}$ per T 75 flask and fed twice weekly with DMEM (4500 mg/L glucose) with $10 \% \mathrm{FBS}, 100 \mathrm{IU} / \mathrm{mL}$ penicillin, $100 \mu \mathrm{g} / \mathrm{mL}$ streptomycin, and $10 \mu \mathrm{M}$ retinoic acid for $5 \mathrm{wk}$. The cells were then split 1:4 and grown for $2 \mathrm{~d}$ more in identical medium without retinoic acid in T 162 flasks. Neuronal cells growing atop a monolayer of non-neuronal cells were dislodged with trypsin and plated in 12-well plates pretreated with polylysine and Matrigel at a density of $3 \times 10^{6}$ cells per well. The cells were then fed weekly for 3 wk more with DMEM, containing 5\% FBS, $100 \mathrm{IU} / \mathrm{mL}$ penicillin, and $100 \mu \mathrm{g} / \mathrm{mL}$ streptomycin, and mitotic inhibitors (10 $\mu \mathrm{M}$ uridine, $10 \mu \mathrm{M}$ 5-fluoro-2'-deoxyuridine, and $1 \mu \mathrm{M}$ cytosine- $\beta$ arabinofuranoside) to reduce the amount of non-neuronal cells. After 3 wk, the cells were fed with identical medium without inhibitors for $1 \mathrm{wk}$.

UCB treatment of NT2-N neurons. Before each experiment, UCB was dissolved in $0.1 \mathrm{M} \mathrm{NaOH}$ and deionized water and added to a BSA solution to obtain a UCB/BSA molar ratio (MR) of 1.5 or 3 . All handling of bilirubin was performed in dim light. Except for experiments performed to compare MTT cleavage at $24 \mathrm{~h}$ (Fig. 1), all experiments were performed with a $1.5 \mathrm{MR}$. Serum free DMEM with high glucose, containing penicillin $100 \mathrm{IU} / \mathrm{mL}$ and streptomycin $100 \mu \mathrm{g} / \mathrm{mL}$ was added to each well before the addition of UCB or control solution. Cells exposed to concentrations of $\mathrm{NaOH}$ and BSA equivalent to the concentrations for cells treated with $100 \mu \mathrm{M} \mathrm{UCB}$ served as controls. $\mathrm{pH}$ in the incubation medium dropped slightly during incubation from an average of $7.59( \pm 0.057)$ before incubation to $7.56( \pm 0.065)$ at $6 \mathrm{~h}$ and to $7.52( \pm 0.054)$ at $24 \mathrm{~h}$. As UCB solubility dropped with decreasing $\mathrm{pH}, \mathrm{pH}$ was not adjusted. In UCB concentrations $\geq 5 \mu \mathrm{M}$, sparse aggregates could be detected in an otherwise homogeneous, UCB-stained incubation medium. UCB/BSA MR 3 displayed more pronounced aggregation. Considerable aggregation was displayed by $0.66 \mu \mathrm{M} \mathrm{UCB}$ without addition of BSA. The cultures were incubated for 6,24 , or $48 \mathrm{~h}$ at $37^{\circ} \mathrm{C}$ in a mixture of $95 \%$ room air and $5 \% \mathrm{CO}_{2}$.

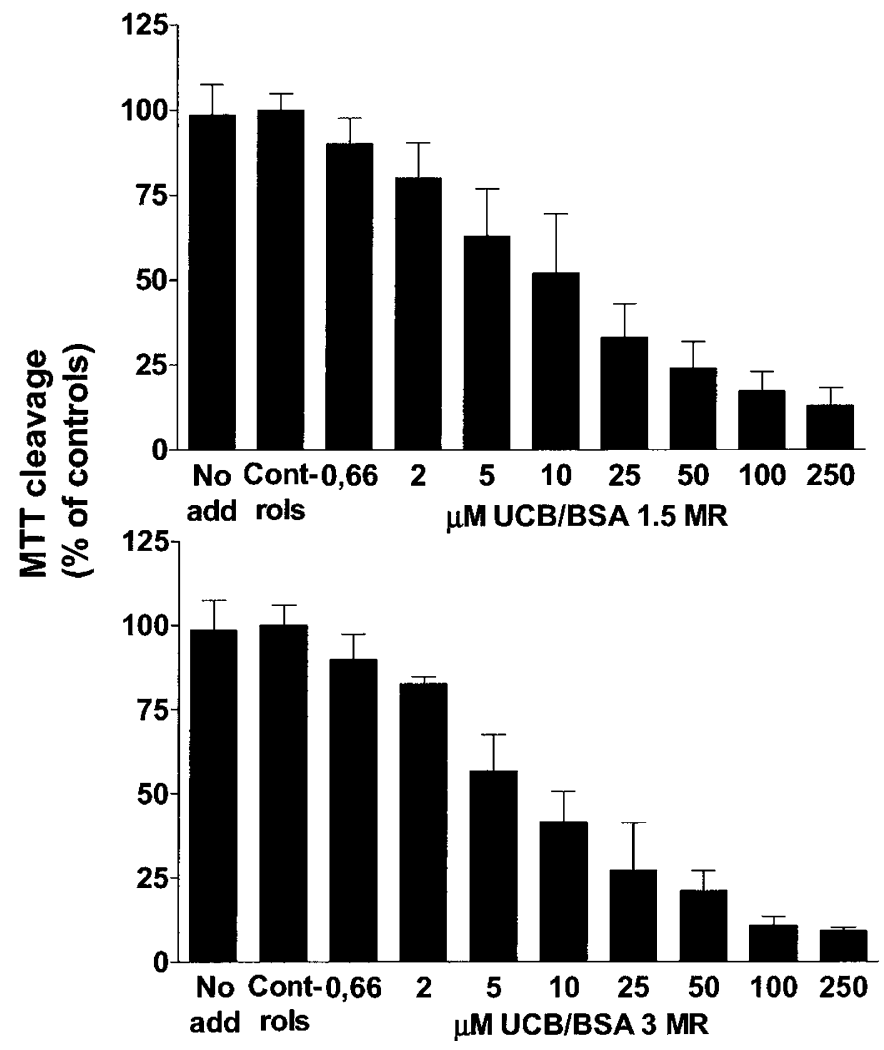

Figure 1. MTT cleavage in NT2-N neurons exposed to different UCB concentrations $(0.66-250 \mu \mathrm{M})$ for $24 \mathrm{~h}$. Two different molar ratios of UCB/ BSA (1.5 and 3) were compared. The concentration of $0.66 \mu \mathrm{M}$ UCB did not contain albumin. All UCB concentrations induced significant reduction in MTT cleavage compared with controls ( $t$ test, $p<0.05$ ). No add (no additives) represents cultures exposed to serum-free medium only. Controls represent the addition of $\mathrm{NaOH}$ and $\mathrm{BSA}$ in doses equivalent to neurons treated with 100 $\mu \mathrm{M}$ UCB. Data are given as means $\pm \mathrm{SD}$.

MTT reduction. After incubation, the medium was aspirated and the cultures were washed twice with PBS. Next, $0.5 \mathrm{~mL}$ of the MTT solution $(0.5$ $\mathrm{mg} / \mathrm{mL})$ was added, and the plates were returned to the incubator $\left(37^{\circ} \mathrm{C}\right.$ in $5 \%$ $\mathrm{CO}_{2}$ ). After $60 \mathrm{~min}$, the MTT solution was aspirated and replaced with $0.5 \mathrm{~mL}$ of DMSO to dissolve the formazan crystals produced by MTT cleavage. Absorbance was read at $570 \mathrm{~nm}$ and background at $660 \mathrm{~nm}$ was subtracted in a Titertek multiscan Plus MK1-ELISA reader, and analyzed by the program Genesis (Labsystems and Life Sciences International Ltd., Haverhill, Sussex, UK). Results are given in percentage of MTT cleavage in controls.

LDH release. $\mathrm{LDH}$ release to the supernatant was assayed with a kit (Roche Molecular Biochemicals, Mannheim, Germany). The sum of the LDH activity in the supernatant and the lysed cells in two wells were used as a measure of total LDH activity for all wells in the actual plate. The measurements were performed at $492 \mathrm{~nm}$ in a Titertek Multiscan Plus MK1-ELISA reader and analyzed by the program Genesis. In separate experiments, $\leq 25 \mu \mathrm{M} \mathrm{UCB}$ was shown not to interfere with the LDH assay when compared with incubation medium alone. The concentration of $100 \mu \mathrm{M}$ UCB distorted the values by $<3 \%$ of the total LDH activity of a typical plate and was not corrected for. In this model, LDH release has been shown to be highly correlated with the energy-failure indicator hypoxanthine (15). $\mathrm{LDH}$ release is expressed as a percentage of total LDH release.

Assessment of nuclear morphology with fluorescent dyes. The combination of the two fluorescent dyes, Hoechst 33342 and EH, was used to assess nuclear morphology and membrane integrity, respectively, as previously described (16). Hoechst 33342 stains the nuclei of all living and dead cells, while nuclei of cells with damaged cell membranes, as seen in necrosis, are stained by EH. All dying and dead cells eventually lose nuclear and plasma membrane integrity, so-called "secondary necrosis" (17). After incubation, the neurons were washed twice with PBS and incubated with the two dyes for $15 \mathrm{~min}$. An 
UV excitation filter (340-380 nm) and a green excitation filter (515-560 nm) were used for each motive. The cells were visualized by an inverted fluorescent microscope (model DM IRB, Leica Microscopy, Herburg, Switzerland) and photographed with a digital camera (Kodak, DC 120 ZOOM Digital Camera, Eastman Kodak, Rochester, NY) for later analysis. Neurons with intact membranes (exclusively stained with Hoechst) displaying uncondensed nuclear chromatin were considered undamaged. Shrunken nuclei with condensed chromatin and intact membranes were labeled as condensed. Nuclei with distinct fragmentation (at least two distinct lobuli) were considered fragmented. Condensed nuclei with uptake of EH were labeled as condensed with disrupted membrane. In general, cells of all categories remained adherent to the dish, and detached nuclei accounted for $<2 \%$ of the total cell count. All cells were counted by the same investigator. A subset of neurons was counted by an independent investigator to an interobserver agreement of $>95 \%$. Prevalence of the different morphologic categories is given in percentage of the total number of cells counted for each experimental condition (at least 800 cells).

DNA fragmentation analysis. After $48 \mathrm{~h}$ of treatment, the cells were treated with trypsin, harvested, centrifuged, washed with cold PBS, centrifuged again, and the supernatant fluid was aspirated before storage at $-70^{\circ} \mathrm{C} . \mathrm{H}_{2} \mathrm{O}_{2}(500$ $\mu \mathrm{M})$ induced total necrotic cell death within $24 \mathrm{~h}$ (microscopic evaluation), and was therefore used as a positive control for necrosis. For analysis, cells were incubated in a hypotonic buffer with a mild detergent $[1 \%$ Triton X-100, $50 \mathrm{~mm}$ Tris- $\mathrm{HCl}$ (pH 7.9), $10 \mathrm{mM}$ EDTA, $50 \mu \mathrm{g} / \mathrm{mL}$ RNase A] for $10 \mathrm{~min}$. Fragmented DNA was separated from intact nuclear DNA by centrifugation for $10 \mathrm{~min}$ at $16,000 \mathrm{~g}$. The fragmented DNA in the supernatant fluid was purified in a Promega wizard PCR Preps DNA Purification System (Promega, Madison, WI) and visualized by agarose gel electrophoresis and ethidium bromide staining.

PARP cleavage. Neurons combined from three wells (a total of $9 \times 10^{6}$ cells) were washed once with PBS, suspended in $150 \mu \mathrm{L}$ of sample buffer ( 62.5 $\mathrm{mM}$ Tris/HCl, $\mathrm{pH}$ 6.8; $6 \mathrm{M}$ urea; $10 \%$ glycerol; $2 \%$ SDS; $0.00125 \%$ bromophenol blue; $5 \% \beta$-mercaptoethanol), sonicated for $15 \mathrm{~s}$, and incubated at $65^{\circ} \mathrm{C}$ for $15 \mathrm{~min}$. Proteins were separated by SDS-PAGE on gels containing $8 \%$ polyacrylamide and blotted (Trans-Blot SD Semi-Dry Transfer Cell; Bio-Rad, Hercules, CA) onto a nitrocellulose membrane (Hybond-C Extra; Amersham Biosciences, Little Chalfont, Buckinghamshire, UK). The membrane was incubated with monoclonal anti-PARP antibodies (BIOMOL, Plymouth, PA), visualized with goat anti-mouse IgG-AP (Santa Cruz Biotechnology, Santa, Cruz, CA) and read with a Kodak scanner (Kodak Digital Science Image Station 440 CF; Eastman Kodak).

STS experiments. STS is a general protein kinase inhibitor that has been widely used to induce apoptosis in many different cell lines. NT2-N neurons were exposed to $2 \mu \mathrm{M}$ STS to serve as a positive control for apoptosis. After 6,24 , or $48 \mathrm{~h}$, cells were analyzed with MTT cleavage, LDH release, and nuclear morphology. DNA electrophoresis and PARP cleavage were performed after $48 \mathrm{~h}$.

Statistics. Data are given as mean $\pm \mathrm{SD}$. Cells from at least eight wells from at least three separate experiments were examined for all experimental conditions except for UCB concentrations and time points where additional experiments where considered without significance (UCB $2 \mu \mathrm{M}$ at $6 \mathrm{~h}, n=6$, and UCB $100 \mu \mathrm{M}$ at $48 \mathrm{~h}, n=3)$. All comparisons between two groups were performed with $t$ tests. Welch correction was applied if the groups had different standard deviations. A two-tailed $p<0.05$ was considered statistically significant. MTT cleavage in neurons treated with UCB/BSA MR of 1.5 and 3 was compared with ANOVA. Bonferroni corrections were not applied.

\section{RESULTS}

MTT cleavage. MTT cleavage was used as a measurement of neuronal viability. Increasing UCB concentrations caused a dose-dependent decrease in neuronal viability as measured with MTT reduction at $24 \mathrm{~h}$ (Fig. 1). There were no differences between controls and neurons treated without additives. UCB/ BSA MR 3 induced significantly more reduction in MTT cleavage at $24 \mathrm{~h}$ than neurons treated with UCB/BSA MR 1.5 $(p<0.0001)$.
As shown in Figure 2, all UCB concentrations (UCB/BSA MR 1.5) induced a decline in MTT cleavage compared with controls already at $6 \mathrm{~h}$. Unlike all higher UCB concentrations, $2 \mu \mathrm{M}$ UCB did not induce further impairment thereafter. During incubation with $2 \mu \mathrm{M}$ STS, MTT cleavage was comparable to values achieved with low UCB concentrations at $6 \mathrm{~h}$, but decreased thereafter to low levels comparable to those seen with UCB concentrations $\geq 25 \mu \mathrm{M}$ UCB.

$\mathrm{LDH}$ release. Loss of cell membrane integrity associated with necrosis was assessed with $\mathrm{LDH}$ release to the supernatant (Fig. 3). A minor increase in LDH release was induced at $24 \mathrm{~h}$ with 2 and $5 \mu \mathrm{M} \mathrm{UCB}$. Treatment with 10 and $25 \mu \mathrm{M}$ UCB induced significant LDH release within $6 \mathrm{~h}$, which continued to increase thereafter. In neurons treated with $100 \mu \mathrm{M} \mathrm{UCB}$, LDH release reached high levels within 6 h $(63 \pm 5 \%)$, indicating a rapid cell demise in the majority of neurons. During STS treatment, LDH release was moderate and reached maximum values at $24 \mathrm{~h}(31 \pm 5 \%)$.

Nuclear morphology. Figure 4 shows a selection of pictures of neurons exposed to different UCB concentrations (UCB/ BSA MR 1.5) or $2 \mu \mathrm{M}$ STS. Figure 5 shows controls (BSA and $\mathrm{NaOH}$ only) displaying a minor loss in undamaged nuclei not different to cells exposed to serum deprivation alone (data not shown). Whereas all UCB concentrations $\geq 5 \mu \mathrm{M}$ induced a moderate but significant loss of undamaged nuclei at $6 \mathrm{~h}$, only $100 \mu \mathrm{M}$ UCB caused morphologic changes in a majority of cells at this time. In all other UCB concentrations and STStreated neurons, the most prominent loss in morphologically undamaged neurons was found between 6 and 24 h. Early morphologic changes $(6 \mathrm{~h})$ were mainly seen as condensed nuclei with disrupted membrane after exposure to UCB concentrations $\geq 10 \mu \mathrm{M}$ UCB. This morphologic appearance dominated in cells treated with 25 and $100 \mu \mathrm{M} \mathrm{UCB}$ at later time points, but only reached $12 \pm 6 \%$ in STS-treated neurons at $48 \mathrm{~h}$. Beyond $6 \mathrm{~h}$, the proportion of fragmented nuclei increased with time throughout the experiment for all UCB concentrations $\leq 10 \mu \mathrm{M}(p<0.05)$. UCB induced a maximum proportion of fragmented nuclei in neurons exposed to $10 \mu \mathrm{M}$ at $48 \mathrm{~h}(37 \pm 11 \%)$, whereas STS induced $61 \pm 6 \%$ fragmentation at this time point. A subset of fragmented nuclei (ap-

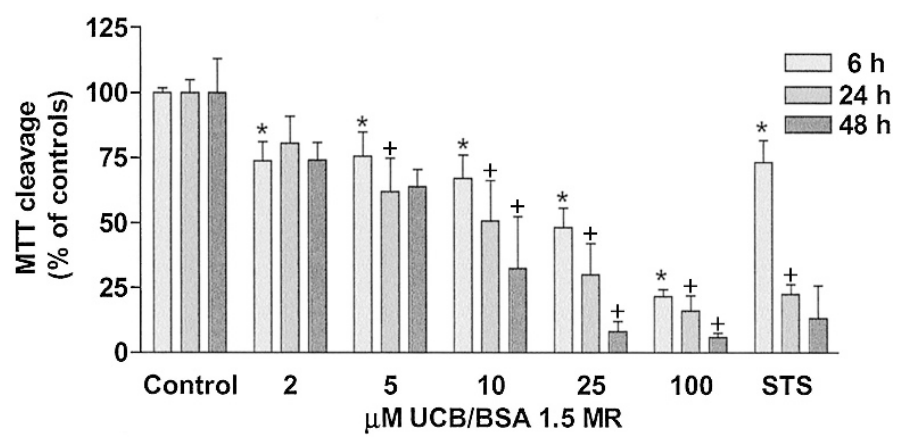

Figure 2. MTT cleavage in percentage of controls after treatment with different UCB concentrations (UCB/BSA molar ratio 1.5) or $2 \mu \mathrm{M}$ STS for 6 , 24 and 48 h. Data are given as means \pm SD. $*(p<0.05)$ denotes the earliest time point when significant difference from controls was reached for each concentration. $\dagger(p<0.05)$ denotes significant difference from the previous time point in cells exposed to the same treatment. 


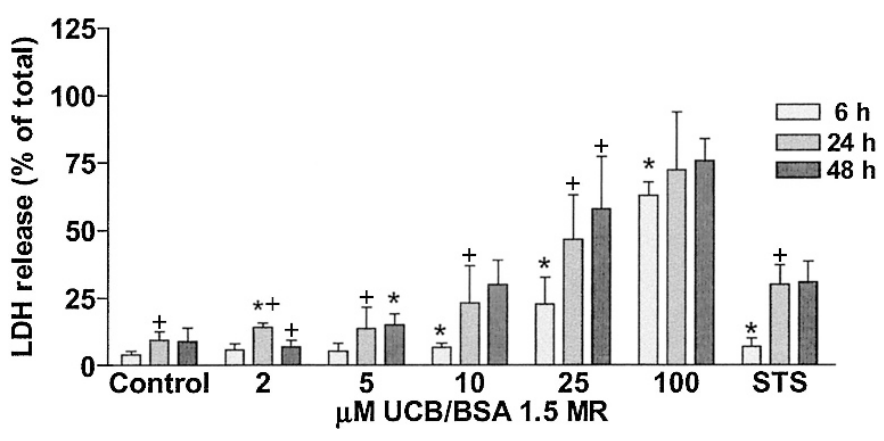

Figure 3. LDH release in percentage of total after treatment with different UCB concentrations (UCB/BSA molar ratio 1.5) or $2 \mu \mathrm{M}$ STS for 6,24 , and $48 \mathrm{~h}$. Data are given as mean $\pm \mathrm{SD} . *(p<0.05)$ denotes the earliest time point when significant difference from controls was reached for each concentration. $\dagger(p<0.05)$ denotes significant difference from the previous time point in cells exposed to the same treatment.

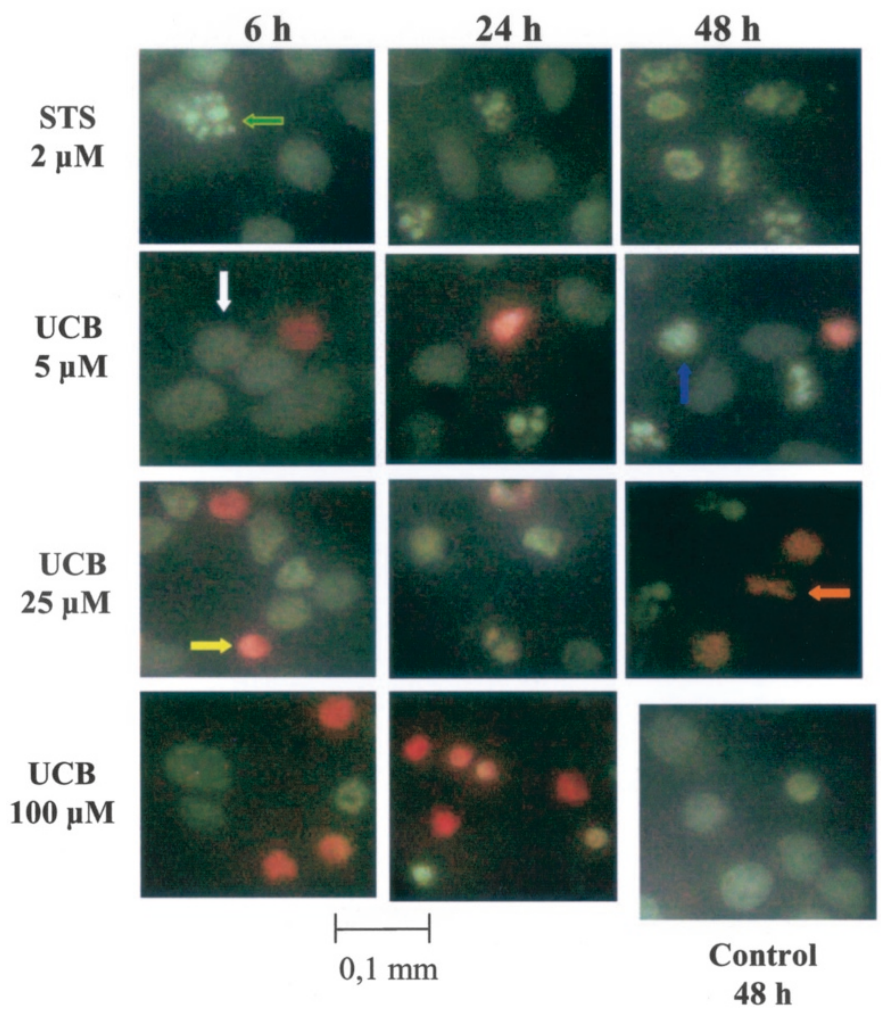

Figure 4. The combination of the two fluorescent dyes Hoechst 33342 (5 $\mathrm{ng} / \mathrm{mL}$ ), and $\mathrm{EH}(\mathrm{EH})(2 \mathrm{nM})$ was used to assess nuclear morphology and membrane integrity respectively after treatment with UCB (UCB/BSA molar ratio 1.5) or $2 \mu \mathrm{M}$ STS after 6, 24 or $48 \mathrm{~h}$. Undamaged nuclei (white arrow), condensed nuclei with preserved cellular membranes (blue arrow), and fragmented nuclei (green arrow) were stained by Hoechst 33342 only. A subset of fragmented nuclei (orange arrow) displayed uptake of $\mathrm{EH}$ as a sign of secondary necrosis. Condensed nuclei with disrupted membranes, displaying uptake of EH (yellow arrow), were considered necrotic.

proximately $25 \%$ irrespective of treatment) displayed uptake of EH as in "secondary necrosis." Neurons exposed to STS and all UCB concentrations $\leq 25 \mu \mathrm{M}$ showed a gradual increase in the proportion of neurons displaying nuclear condensation until $24 \mathrm{~h}$, which was stable thereafter.

DNA electrophoresis. DNA fragmentation is considered a hallmark in apoptosis, however, the extent varies greatly (18). STS induced high molecular weight (HMW) DNA fragments,
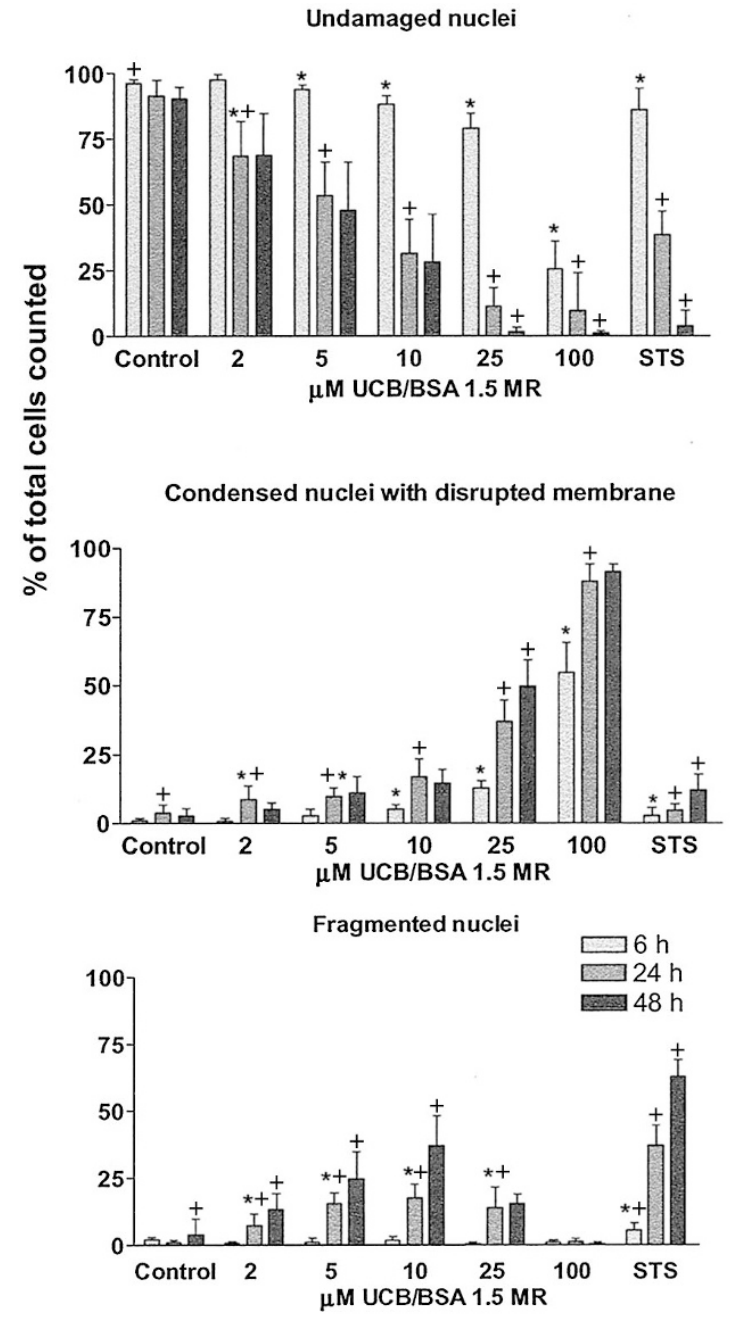

Condensed nuclei

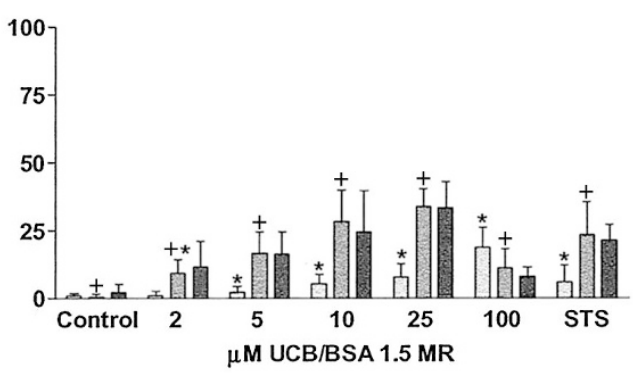

Figure 5. Nuclear morphology in percentage of total cells counted for different UCB concentrations (UCB/BSA molar ratio 1.5) or $2 \mu \mathrm{M}$ STS after 6,24 , or 48 h. Data are given as mean \pm SD. $*(p<0.05)$ denotes the earliest time point when significant difference from controls was reached for each concentration. $\dagger(p<0.05)$ denotes significant difference from the previous time point in cells exposed to the same treatment.

and distinct DNA laddering after $48 \mathrm{~h}$ (Fig. 6). Five micromolar UCB (UCB/BSA MR 1.5) induced HMW DNA fragments and a faint but distinct DNA ladder not seen after treatment with higher UCB concentrations. There was a dose-dependent loss in the fraction of HMW fragments in cells treated with 10 and $25 \mu \mathrm{M}$ UCB. Neither treatment with $100 \mu \mathrm{M}$ UCB nor necrosis control $\left(500 \mu \mathrm{M} \mathrm{H}_{2} \mathrm{O}_{2}\right)$ induced DNA fragmentation. 


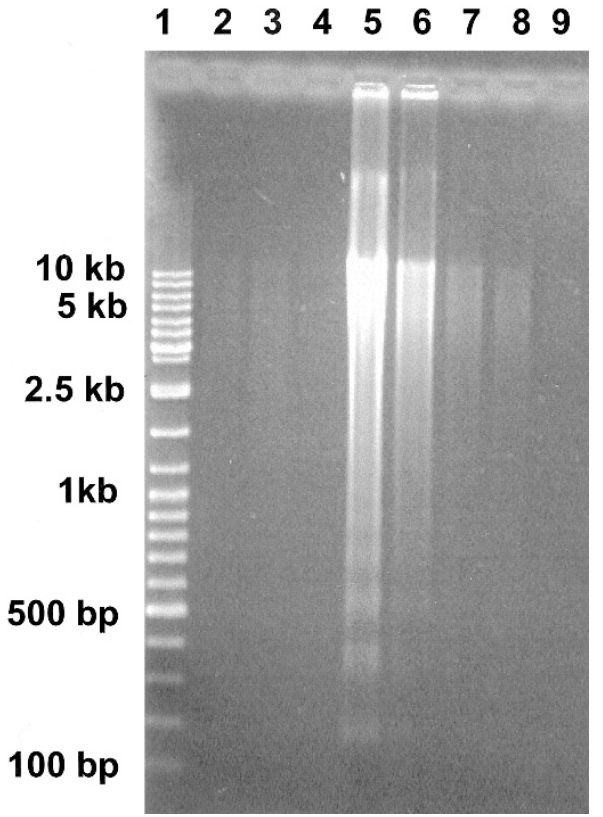

Figure 6. DNA electrophoresis after incubation with different UCB concentrations (UCB/BSA molar ratio 1.5) or $2 \mu \mathrm{M}$ STS for $48 \mathrm{~h}$. Lane 1, DNA markers; lane 2, cells incubated in medium without additives; lane 3, cells from control cultures (incubated with $\mathrm{BSA} / \mathrm{NaOH}$ only); lane 4, cells treated with $500 \mu \mathrm{M} \mathrm{H}_{2} \mathrm{O}_{2}$ (necrosis control); lane 5, cells treated with $2 \mu \mathrm{M}$ STS (apoptosis control); lanes 6-9, cells treated with UCB 5, 10, 25, and $100 \mu \mathrm{M}$. High molecular weight (HMW) fragments were induced by STS and UCB $\leq 25 \mu \mathrm{M}$. Only STS and $5 \mu \mathrm{M}$ UCB induced bands of small DNA fragments (DNA ladder).

PARP Cleavage. Proteolytic cleavage of PARP from a $116-\mathrm{kDa}$ polypeptide to an $85-\mathrm{kDa}$ fragment is an important event in at least one apoptotic pathway (19). Western blots demonstrated a strong presence of the $85-\mathrm{kDa}$ fragment after STS treatment at $48 \mathrm{~h}$ (Fig. 7). Faint but distinct PARP cleavage was also visible after treatment with $5 \mu \mathrm{M} \mathrm{UCB}$, but not for higher concentrations (UCB/BSA MR 1.5), nor in controls.

\section{DISCUSSION}

The principal findings of the present study were that low and moderate UCB concentrations induced early necrosis in a

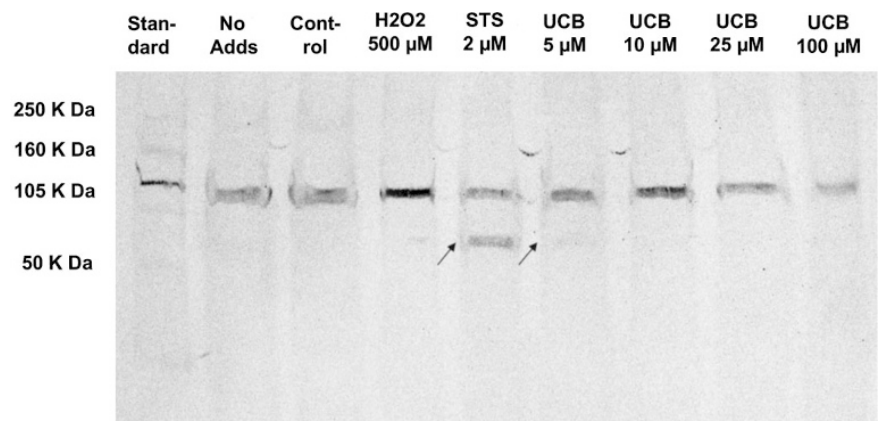

Figure 7. Western blot analysis of PARP in NT2-N neurons after $48 \mathrm{~h}$ incubation with different UCB concentrations (UCB/BSA molar ratio 1.5) or 2 $\mu \mathrm{M}$ STS. The band at $116 \mathrm{~K}$ is intact PARP and the band at $85 \mathrm{~K}$ represents the cleaved fragment. STS and UCB $5 \mu \mathrm{M}$ cleaved PARP (arrows). PARP cleavage was not seen in cells treated with $\mathrm{UCB} \geq 10 \mu \mathrm{M} \mathrm{UCB}$, in necrosis controls $\left(500 \mu \mathrm{M} \mathrm{H}_{2} \mathrm{O}_{2}\right)$, or in negative controls. subset of neurons followed by late apoptosis-like cell death in human NT2-N neurons. Higher concentrations of UCB induced rapid metabolic demise and necrotic cell death. These results are in accordance with numerous in vitro studies showing that exposure to a variety of different toxic stimuli such as glutamate, methylmercury, or acidosis induce early necrotic cell death or late apoptotic cell death, depending on the intensity of the insult (20-22).

Little is known about which brain bilirubin concentrations are required under what conditions to cause damage in vivo. However, autopsy material and electrophysiological studies indicate that brain bilirubin concentrations may exceed $25 \mu \mathrm{M}$ $(23,24)$. A main concern in the study of UCB toxicity in vitro is to keep the bilirubin molecule in solution, as the aqueous solubility of UCB has been estimated as low as $70 \mathrm{nM}(25)$. The most common approach to this problem has been to add albumin. In the present study, experiments with UCB/BSA MR of 3 induced a slightly greater reduction of cell viability as measured with MTT reduction than MR 1.5 at $24 \mathrm{~h}$. This difference was smaller than expected, possibly due to a more pronounced aggregation of unbound bilirubin for the higher MR, confirmed by light microscopy. All further experiments were performed with a UCB/BSA MR of 1.5. Consequently, the total bilirubin level overestimates the levels of unbound bilirubin during incubation.

BSA, as used in the present study, has a lower affinity for UCB than HSA (26). On the other hand, BSA-bound UCB have shown slower rates of dissociation and cellular interactions in cultured hepatoblastoma cells (26). Furthermore, UCB affinity for HSA is dependent on impurities of UCB and on buffer composition, and is inversely correlated to HSA concentrations (27). How this applies to UCB affinity for BSA is not settled. Hence, due to differences in binding affinities, and the fact that UCB often forms metastable solutions where the precipitation level is unpredictable, the choice of species of albumin may influence toxicity of UCB in otherwise identical conditions. In the present study, a stepwise increase in total bilirubin with a fixed UCB/BSA MR (1.5) induced a graded toxic effect of bilirubin, indicating a proportional increase also for the unbound fraction of UCB.

The execution of apoptosis is an energy-requiring process (3). In neurons treated with $\leq 10 \mu \mathrm{M} \mathrm{UCB}$, metabolic activity was maintained as measured by MTT cleavage throughout the observation period, concomitant with nuclear fragmentation and condensation compatible with apoptosis. Despite almost total cell death at $48 \mathrm{~h}(>94 \%)$, as indicated by nuclear morphology, LDH release was moderate after treatment with STS. A possible explanation for this finding is that apoptosis results in a compaction of the cell membrane without the spillage of cell contents into the culture medium before secondary necrosis (17). All UCB concentrations induced a significant proportion of condensed nuclei with disrupted membrane and a significant increase in LDH release compared with controls within $24 \mathrm{~h}$, consistent with a component of early necrotic cell death. Neurons treated with $25 \mu \mathrm{M}$ UCB, however, displayed a coexistence of a variety of different shapes not entirely typical of apoptosis or necrosis combined with a 
late LDH release, suggesting a component of secondary necrosis.

DNA fragmentation in apoptosis is a two-step process in which DNA is first cleaved into large fragments of $50-300 \mathrm{~kb}$ (HMW fragments) that subsequently are cleaved into smaller oligonucleosomes (the DNA ladder) (18). Only the first step is considered essential in apoptosis (18). NT2-N neurons have been reported never to produce DNA ladders, although morphologic changes consistent with apoptosis can be induced (19). In the present study, $5 \mu \mathrm{M}$ UCB, like STS, induced not only HMW fragments, but also DNA ladders; 10 and $25 \mu \mathrm{M}$ UCB induced HMW fragments only. This finding further substantiates that low and moderate UCB concentrations induce apoptosis-like cell death. PARP cleavage by caspase- 3 is vital for the appropriate function of the apoptotic machinery in at least one pathway to apoptosis (19). PARP cleavage induced by $5 \mu \mathrm{M}$ UCB (and STS), as found in the present study, indicates a possible role for caspase-3 in bilirubin-mediated apoptosis in human NT2-N neurons.

The present study is the first to investigate the relation between UCB-induced apoptosis and necrosis in a human neuronal cell line. The importance of species differences was recently underscored when tumor necrosis factor-related apoptosis-inducing ligand was found to induce apoptosis in human CNS (28). Previously, this agent had been thought to be safe as it did not cause neuronal damage in laboratory animals. In general, our findings are in agreement with previous findings in nonhuman cells. Seubert et al. (9) investigated UCB-induced cell death (1-100 $\mu \mathrm{M}$ UCB and a fixed concentration of $40 \mu \mathrm{M}$ BSA) in three different murine hepatoma cell lines. Assessed with nuclear morphology, they found a dose-dependent increase of both apoptosis and necrosis at $24 \mathrm{~h}$, with an increase in the relative proportion of necrotic cells at higher concentrations. In a study on cortical neurons from newborn rats by Grojean et al. (5), $0.4 \mu \mathrm{M}$ UCB (without added albumin) induced predominately apoptotic cell death (16\% apoptotic versus $8 \%$ necrotic cells at $96 \mathrm{~h}$ ). On the other hand, relatively high UCB concentrations (17 and $86 \mu \mathrm{M}$ UCB/HSA MR 3) were recently reported to induce apoptosis in fetal rat neurons after only $4 \mathrm{~h}(8)$.

In conclusion, the present study demonstrated that UCB induces delayed apoptosis and early necrosis in human NT2-N neurons. In neurons exposed to low UCB concentrations $(\leq 10$ $\mu \mathrm{M})$, apoptosis was the major form of cell death. The shift in cell death mechanisms within a clinically relevant concentration range, as found in the present study, urges further in vitro and in vivo investigations in the hope that a better knowledge of UCB toxicity may yield novel therapeutic approaches.

Acknowledgments. The authors thank Arild Holt and Christine Gran for their excellent technical assistance.

\section{REFERENCES}

1. Hansen TW 2000 Kernicterus in term and near-term infants - the specter walks again. Acta Paediatr 89:1155-1157

2. Silva RF, Rodrigues CM, Brites D 2002 Rat cultured neuronal and glial cells respond differently to toxicity of unconjugated bilirubin. Pediatr Res 51:535-541

3. Leist M, Nicotera P 1998 Apoptosis, excitotoxicity, and neuropathology. Exp Cell Res 239:183-201

4. Bonfoco E, Krainc D, Ankarcrona M, Nicotera P, Lipton SA 1995 Apoptosis and necrosis: two distinct events induced, respectively, by mild and intense insults with $\mathrm{N}$-methyl-D-aspartate or nitric-oxide/superoxide in cortical cell-cultures. Proc Natl Acad Sci U S A 92:7162-7166

5. Grojean S, Koziel V, Vert P, Daval JL 2000 Bilirubin induces apoptosis via activation of NMDA receptors in developing rat brain neurons. Exp Neurol 166:334-341

6. Rodrigues CM, Sola S, Brites D 2002 Bilirubin induces apoptosis via the mitochondrial pathway in developing rat brain neurons. Hepatology 35:1186-1195

7. Silva R, Rodrigues CMP, Gulbenkian S, Brites D 1998 Bilirubin-induced apoptosis in astrocytes is prevented by ursodeoxycholic acid. Hepatology 28:329A

8. Silva RF, Rodrigues CM, Brites D 2001 Bilirubin-induced apoptosis in cultured rat neural cells is aggravated by chenodeoxycholic acid but prevented by ursodeoxycholic acids. J Hepatol 34:402-408

9. Seubert JM, Darmon AJ, El-Kadi AO, D'Souza SJ, Bend JR 2002 Apoptosis in murine hepatoma Hepa 1c1c7 wild-type, $\mathrm{C} 12$, and $\mathrm{C} 4$ cells mediated by bilirubin. Mol Pharmacol 62:257-264

10. Pleasure SJ, Lee VM 1993 NTera-2 cells: a human cell-line which displays characteristics expected of a human committed neuronal progenitor cell. J Neurosci Res 35:585-602

11. Younkin DP, Tang CM, Hardy M, Reddy UR, Shi QY, Pleasure SJ, Lee VM, Pleasure D 1993 Inducible expression of neuronal glutamate receptor channels in the NT2 human cell line. Proc Natl Acad Sci U S A 90:2174-2178

12. Neelands TR, King AP, Macdonald RL 2000 Functional expression of L-, N-, P/Qand R-type calcium channels in the human NT2-N cell line. J Neurophysiol 84:29332944

13. Guillemain I, Alonso G, Patey G, Privat A, Chaudieu I 2000 Human NT2 neurons express a large variety of neurotransmission phenotypes in vitro. J Comp Neurol 422:380-395

14. Rootwelt T, Dunn M, Yudkoff M, Itoh T, Almaas R, Pleasure D 1998 Hypoxic cell death in human NT2-N neurons: involvement of NMDA and non-NMDA glutamate receptors. J Neurochem 71:1544-1553

15. Almaas R, Saugstad OD, Pleasure D, Rootwelt T 2000 Effect of barbiturates on hydroxyl radicals, lipid peroxidation, and hypoxic cell death in human NT2-N neurons. Anesthesiology 92:764-774

16. Almaas R, Pytte M, Lindstad JK, Wright M, Saugsatd OD, Plerasure D, Rootwelt T 2003 Acidosis has opposite effects on neuronal survival during hypoxia and reogygenation. J Neurochem 84:1018-1027

17. Kaal EC, Veldman H, Sodaar P, Joosten EA, Bar PR 1998 Oxidant treatment causes a dose-dependent phenotype of apoptosis in cultured motoneurons. J Neurosci Res 54:778-786

18. Walker PR, Leblanc J, Carson C, Ribecco M, Sikorska M 1999 Neither caspase-3 nor DNA fragmentation factor is required for high molecular weight DNA degradation in apoptosis. Ann N Y Acad Sci 887:48-59

19. Joashi UC, Greenwood K, Taylor DL, Kozma M, Mazarakis ND, Edwards AD, Mehmet H 1999 Poly(ADP ribose) polymerase cleavage precedes neuronal death in the hippocampus and cerebellum following injury to the developing rat forebrain. Eur J Neurosci 11:91-100

20. Ankarcrona M, Dypbukt JM, Bonfoco E, Zhivotovsky B, Orrenius S, Lipton SA, Nicotera P 1995 Glutamate-induced neuronal death: a succession of necrosis or apoptosis depending on mitochondrial-function. Neuron 15:961-973

21. Castoldi AF, Barni S, Turin I, Gandini C, Manzo L 2000 Early acute necrosis, delayed apoptosis and cytoskeletal breakdown in cultured cerebellar granule neurons exposed to methylmercury. J Neurosci Res 59:775-787

22. Ding D, Moskowitz SI, Li R, Lee SB, Esteban M, Tomaselli K, Chan J, Bergold PJ 2000 Acidosis induces necrosis and apoptosis of cultured hippocampal neurons. Exp Neurol 162:1-12

23. Claireaux AE, Cole PG, Lathe GH 1953 Icterus of the brain in the newborn. Lancet 265:1226-1230

24. Wennberg RP, Hance AJ 1986 Experimental bilirubin encephalopathy: importance of total bilirubin, protein binding, and blood brain barrier. Pediatr Res 20:789-792

25. Ostrow JD, Pascolo L, Tiribelli C 2003 Reassessment of the unbound concentrations of unconjugated bilirubin in relation to neurotoxicity in vitro. Pediatr Res 54:98-104

26. Zucker SD, Goessling W 2000 Mechanism of hepatocellular uptake of albuminbound bilirubin. Biochim Biophys Acta 1463:197-208

27. Weisiger RA, Ostrow JD, Koehler RK, Webster CC, Mukerjee P, Pascolo L, Tiribelli C 2001 Affinity of human serum albumin for bilirubin varies with albumin concentration and buffer composition: results of a novel ultrafiltration method. J Biol Chem 276:29953-29960

28. Nitsch R, Bechmann I, Deisz RA, Haas D, Lehmann TN, Wendling U, Zipp F 2000 Human brain-cell death induced by tumor-necrosis-factor-related apoptosis-inducing ligand (TRAIL). Lancet 356:827-828 